\title{
微分スペクトル法による作物中のオキシン銅の残留分析
}

\author{
小野成男, 山崎悦子 \\ 日本曹達株式会社ファインケミカル研究所 \\ (昭和 57 年 6 月 18 日受理)
}

\section{Residue Analysis of Copper 8-quinolinolate by Derivative Spectrophotometry}

\author{
Shigeo Ono and Etsuko Yamazaki \\ Fine Chemicals Research Laboratory, Nippon Soda Co., Ltd., \\ Takada, Odawara 250-02, Japan
}

\begin{abstract}
Application of derivative spectrophotometry to residue analysis of copper 8-quinolinolate in crops was investigated. The result showed that the derivative spectrophotometry was more suitable than colorimetry, atomic absorption spectrometry and high performance liquid chromatography which were already published. Copper 8-quinolinolate was extracted with acidic methanol from crops. After addition of $1 \%$ sodium chloride solution to the methanol extract, the mixture was washed with $n$-hexane. After neutralizing, the aqueous methanol solution was extracted with dichloromethane. Finally, the pesticide in the dichloromethane solution was re-extracted with $1 \mathrm{~N}$ hydrochloric acid. Fourth derivative spectrum of the acidic solution was recorded by a Hitachi spectrophotometer type 330. The amount of copper 8-quinolinolate was proportional to the difference absorbance $\left(\Delta A=A_{252}-A_{261}\right)$ within the range of $0-0.3 \mathrm{ppm}$. The detectable limit of copper 8-quinolinolate was $0.04 \mathrm{ppm}$ when $50 \mathrm{~g}$ of sample was used. Average recovery was about $95 \%$.
\end{abstract}

\section{緒}

\section{言}

作物中のオキシン銅 (copper 8-quinolinolate) の残留 分析法として, $p$-ニトロベンゼンジアゾニウム塩とカッ プリングさせて定量する比色法，銅を定量する原子吸光 光度法およびケイ光検出器付高速液体クロマトグラフ法 がすでに知られている ${ }^{1,2)}$. オキシン銅はきわめて強い 吸収带を紫外部に有するため, 紫外吸光光度法はきわめ て有効な手段であるが，極大吸収波長は $252 \mathrm{~nm}$ と比 較的短波長領域にあるため, 通常の吸光光度法では植物 成分の妨害を受けやすく, 残留分析における定量法とし て探用しにくかった．このため, 微分スペクトル法を適 用した結果, 植物からの妨害成分の吸収帯が消去でき, 水蒸気蒸留や濃縮操作など一切不要なきわめて迅速簡便 な残留分析法を作成することができたので報告する.

\section{分析法}

\section{1. 試薬および機器}

一般の試薬類は特級品をそのまま使用した。 セライト: Johns-Manville 製 No. 545

液相分離濾紙：ワットマン 1 PS

オキシン銅：純度 $96.4 \%$

ホモジナイザー：ポリトロン(キネマチカ社製)

分光光度計：日立分光光度計 330 形, $1 \mathrm{~cm}$ 角形石英 セル使用

\section{2. 微分スペクトルの測定条件}

微分次数： 4 次

微分波長差: $8 \mathrm{~nm}$

走查速度： $30 \mathrm{~nm} / \mathrm{min}$

吸光度範囲: $-0.5 \sim+0.5$ 


\section{3. 検量線の作成}

オキシン銅の $1 \mathrm{~N}$ 塩酸溶液 $(10 \mathrm{ppm}) 0.5,1.0,2.0$

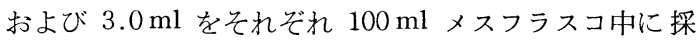
取し， $1 \mathrm{~N}$ 塩酸で $100 \mathrm{~m}$ ! とする. 溶液を $1 \mathrm{~cm}$ 角形石 英セルに入れ，上記した測定条件で $230 \sim 300 \mathrm{~nm}$ の領 域で 4 次微分スペクトルを測定する. $252 \mathrm{~nm}$ の山と $261 \mathrm{~nm}$ の谷々の吸光度差 $\Delta A$ を縦軸に，才キシン銅の 濃度を横軸にとり検量線を作成する。

\section{4. 分析操作}

細切りにした作物 $50 \mathrm{~g}$ をステンレス容器内に科り取 り,メタノール $100 \mathrm{ml}$ と $1 \mathrm{~N}$ 塩酸 $3 \mathrm{ml}$ を加光, ポリ トロンホモジナイザーで磨砕抽出する，セライトを 1 $2 \mathrm{~cm}$ の厚さに敷き，内容物を吸引滤過する. 残渣を 50 $\mathrm{ml}$ のメタノールで洗浄し, 吸引濾過する，濾液を合わ せ $1 \%$ 塩化ナトリウム溶液 $100 \mathrm{ml}$ を加えて, $100 \mathrm{ml}$ の $n$-ヘキサンで 2 回振とうし洗浄する。洗浄液は捨てる。 水・メタノール液を中和 $(\mathrm{pH}$ 6.5 7) した後, 塩化メ チレン $100 \mathrm{ml}$ で 1 回， $50 \mathrm{ml}$ で 1 回振とう抽出する. 㙁化メチレン抽出液を合わせ軽く水洗した後, 液相分離 滤紙を通して脱水する. $1 \mathrm{~N}$ 塩酸 $100 \mathrm{ml}$ で振とう抽出 し，塩酸首を $1 \mathrm{~cm}$ 石英セルに入れる. 以下検量線の作 成方法に従って操作し，オキシン銅の残留量を求める. 操作法の概要を Fig. 1 に示す.

\section{実験}

\section{1. 測定溶媒の選定}

オキシン銅の吸収スペクトル測定用の溶媒について検 討した.オキシン銅の極大吸収波長は $250 \mathrm{~nm}$ 付近にあ るため，塩素系溶媒の使用は困難であった，n一へキサン には難溶であったため, メタノールと希塩酸について紫

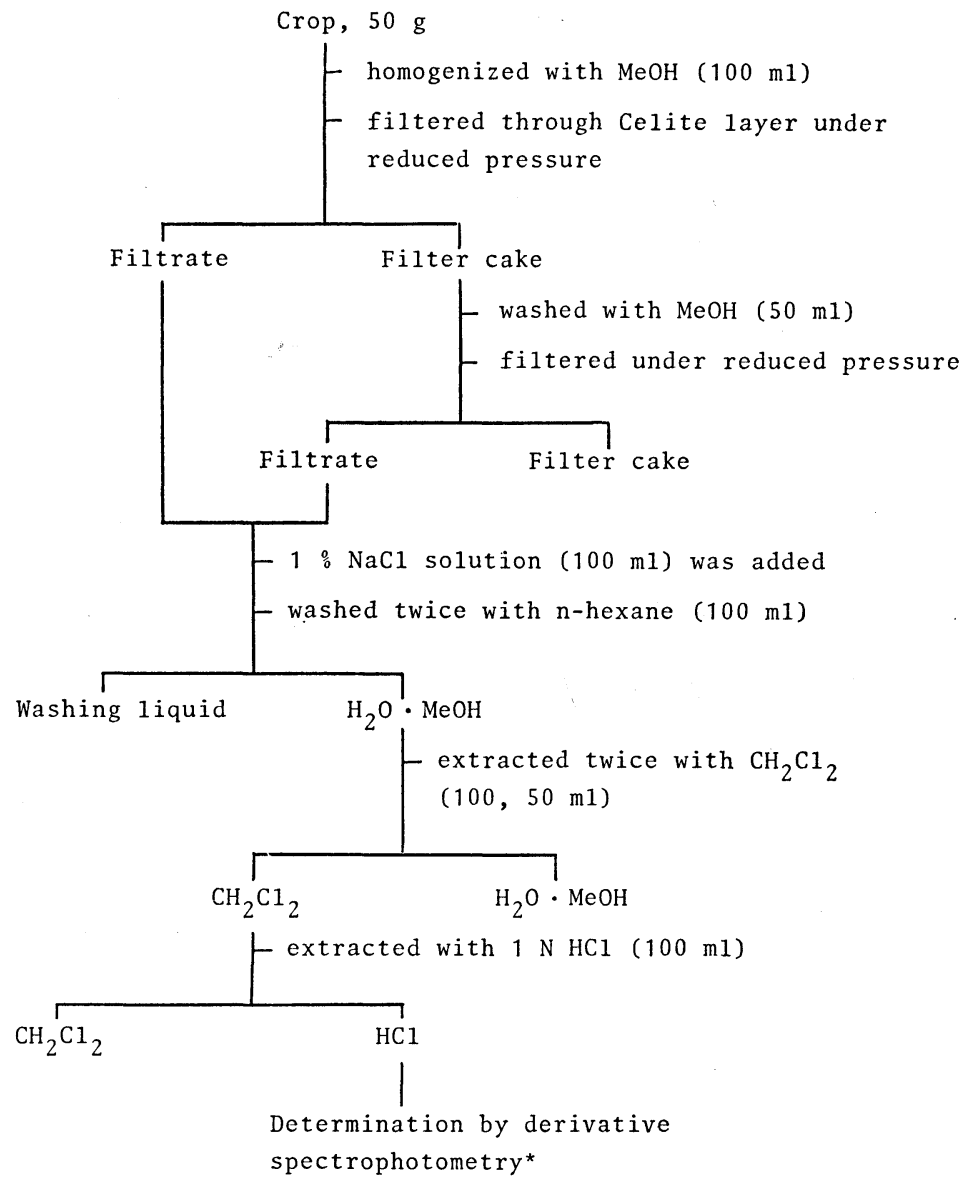

Fig. 1 Flow diagram of analytical method for copper 8-quinolinolate in crops.

* Operating conditions: order of differentiation 4 th, derivative wave length difference $(\Delta \lambda) 8 \mathrm{~nm}$, absorbance range \pm 0.5 , scanning speed $30 \mathrm{~nm} / \mathrm{min}$. 
外部吸収スペクトルを測定した結果，希塩酸溶液の場合 スペクトルの形状も良好で, 吸収も強く, 分子吸光係数 は約 $7.3 \times 10^{1}$ であった.メタノール溶液では吸収は少 し弱かった (約 $\left.6.2 \times 10^{4}\right)$. このためスペクトル測定用 の溶媒として $1 \mathrm{~N}$ 塩酸を使用することにした.

\section{2. 微分スペクトルの測定条件}

$1 \mathrm{~N}$ 塩酸溶液中でオキシン銅の吸収スペクトルおよび その微分スペクトルを測定した結果は Fig. 2 のとおり である.この結果, 微量のオキシン銅の定量には 4 次微 分スペクトルが適していることがわかった４ 次微分の 場合, スペクトルの山は $252 \mathrm{~nm}$ に, 谷は $261 \mathrm{~nm}$ に現 われたので，この 2 波長を定量波長に選んだ.この波長 において吸光度差 $\Delta A\left(A_{252}-A_{261}\right)$ とオキシン銅の濃度 との間の関係線を求めた結果, 直線が得られたのでこれ を検量線とした．微分波長差 $\Delta \lambda$ を大きく選ぶ汪ど, $\Delta A$ は増強されたが，上記分析法で処理して得られた塩酸溶 液中の植物成分と共存している 8-ヒドロキシキノリン の吸収スペクトルのみを選択的にとり出す，いわゆる抽 出効果は $\Delta \lambda$ を $8 \mathrm{~nm}$ にした場合が最も効果的であった。

\section{3. クリンアップの検討}

すでに報告されている各種のオキシン銅の残留分析 法1,2) では, 分析操作として数回の抽出溶媒の濃縮が必 要であり,さらに環境庁告示の方法では水蒸気蒸留も必

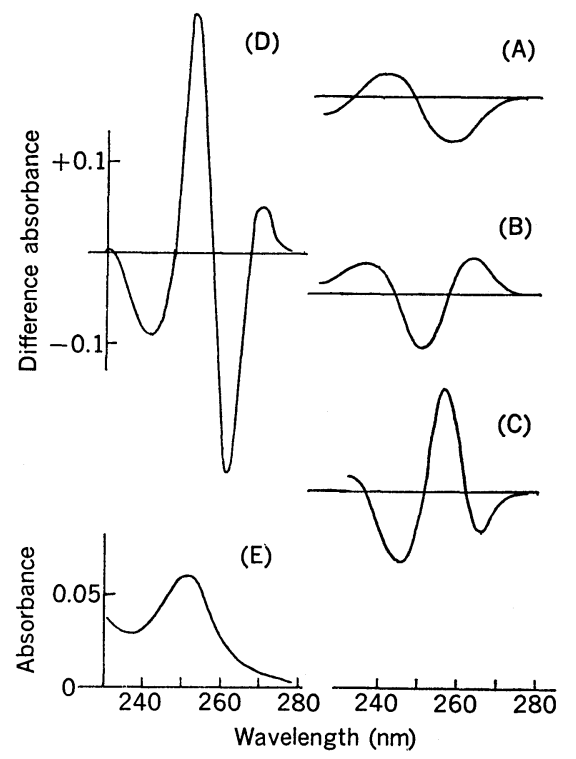

Fig. 2 Absorption and derivative spectra of copper 8-quinolinolate in $1 \mathrm{~N} \mathrm{HCl}$.

Original spectrum: (E) concentration $0.2 \mathrm{ppm}$.

Derivative spectra: (A) 1st, (B) 2nd, (C) 3rd,

(D) 4 th, $\Delta \lambda=8 \mathrm{~nm}$.
要とするなど，分析にやや長時間を必要とした．本報で は, 液液分配以外のクリンアップ操作を一切行なわない 簡便な方法を検討した．オキシン銅は塩酸酸性溶液に可 溶であったので, 最初の抽出溶媒として塩酸添加のメ夕 ノールを選んだ. 抽出後水を加えて酸性の水メタノール 溶液とし, 等量の $n$-ヘキサンを加えて振とうした場合, ヒドロキシキノリンは $n$-ヘキサン層に分配されず，へ キサン洗浄が可能であった. $n$ 一ヘキサンの代りに塩化メ チレンを使用した場合，一部は塩化メチレン層に分配さ れたため, 塩化メチレン首を新しい希塩酸で振とうして 逆抽出する必要があった。中和した水・メタノールと塩 化メチレンの分配ではヒドロキシキノリンは定量的に塩 化メチレン凲に存在した. また塩化メチレン中のヒドロ キシキノリンは $1 \mathrm{~N}$ 塩酸で定量的に抽出された.これ らの液液分配を組み合わせた結果, 上記分析法に示した ように，きわめて簡単な操作で十分定量が可能であっ た. オキシン銅の希塩酸溶液中での 4 次微分スペクトル の $\Delta A$ は大きいので, 最終液量が多くても定量に支障 がないため溶媒の濃縮操作は一切不要であった. 最終溶 液中にはなおかなりの植物成分が混在しているため, 通 常の吸光光度法では定量が困難であった。

\section{4. 検出限界および添加回收率}

$50 \mathrm{~g}$ の無処理区試料を前記した分析操作に従って処理 して得られた塩酸溶液の $\Delta A$ は 0.015 であったのでこ の值の約 3 倍の 0.05 (高さ約 $12 \mathrm{~mm}$ ) を最小検出吸光 度差とした。これはオキシン銅の濃度 $0.02 \mathrm{ppm}$ に相当 する. 最終液量が $100 \mathrm{ml}$, 試料科取量が $50 \mathrm{~g}$ であるの で，検出限界は $(0.02 \times 100) \div 50=0.04 \mathrm{ppm}$ となる. 環境庁告示法によるオキシン銅の残留分析法の検出限界 は約 $0.04 \mathrm{ppm}$ であるので, 本報の検出限界は十分に実 用性のあるものと考兄られた. Fig. 3 に無処理区試料お よびオキシン銅が存在する場合の微分スペクトルを示

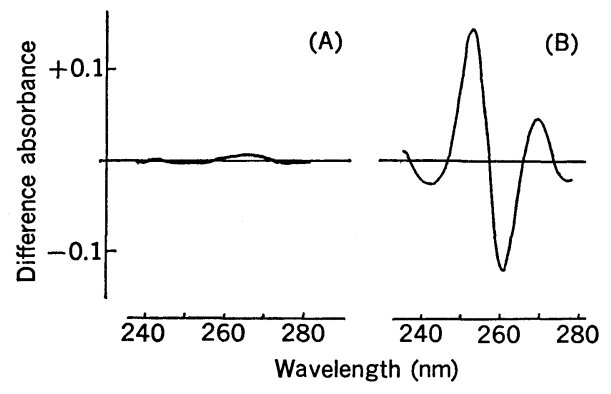

Fig. 3 Examples of 4 th derivative spectra. A: Unfortified onion sample, B: Fortified onion sample $(10 \mu \mathrm{g})$. 
Table 1 Recoveries of copper 8-quinolinolate.

\begin{tabular}{cccccccc}
\hline \multirow{2}{*}{ Sample } & \multicolumn{9}{c}{ Recovery $(\%)$} & \multicolumn{2}{c}{ C.V. $(\%)$} \\
\cline { 2 - 6 } & \multicolumn{9}{c}{$(X)$} & & $(\bar{X})$ & 1.7 \\
Onion & 98.2, & 96.2, & 96.0, & 94.2, & 98.0 & 96.5 & 1.7 \\
Apple & 96.2, & 94.6, & 94.0, & 95.4, & 92.0 & 94.4 & 2.2 \\
Pear & 96.0, & 92.0, & 94.0, & 94.6, & 90.8 & 93.5 & \\
\hline
\end{tabular}

Sample weight $50 \mathrm{~g}$, fortified amount $10 \mu \mathrm{g}$.

す.オキシン銅を添加し，前記した方法に従って全操作 を行ない回収率を測定した結果を Table 1 に示す.

\section{考察}

著者はすでに微分スペクトル法の農薬残留分析への応 用として，作物および土畩中のチオファネートメチルの 残留分析に適用し ${ }^{3)}$ ，良好な結果を得ている. オキシン 銅は希塩酸溶液中で極大吸収波長が $252 \mathrm{~nm}$ と比較的短 波長側ではあるが，きわめて強い吸収带（分子吸光係数 $\left.\varepsilon=7.3 \times 10^{4}\right)$ を有し，しかも吸収スペクトルが鋭い形状 を示している点に着目して微分スペクトル法を適用し た.この結果, 微分スペクトル法で作物中のオキシン銅 を定量する場合，簡単な液液分配の久で定量可能であ り, 濃縮操作や水蒸気蒸留操作など一切必要とせず, 水 蒸気蒸留後高速液体クロマトグラフで定量する方法と比 較して分析所要時間は約半分であり,さらに高速液体ク ロマトグラフ法の測定前の準備に要する時間を考虑する と微分スペクトル法はきわめて迅速な分析法ということ ができる、オキシン銅をチオファネートメチルとの混合 剂で作物に散布する場合, チオファネートメチルの一部
は 2-メチルベンズイミダゾリルカーバメート（以下 $\mathrm{MBC}$ と略す) として残留することが予想され4), 前記し たオキシン銅の 分析法で処理した場合，オキシン銅と $\mathrm{MBC}$ は同じ挙動を示し，最終液である $1 \mathrm{~N}$ 塩酸溶液中 には両者が存在する。しかも $\mathrm{MBC}$ は紫外部に強い吸収 $\left(\varepsilon: 1.6 \times 10^{1}\right)$ を示すため, 通常の紫外吸光光度法では オキシン銅の定量を妨害する.しかし，微分スペクトル 法を採用する場合，希塩酸溶液中での $\mathrm{MBC}$ の 4 次微分 スペクトル ${ }^{3)}$ は $270 \sim 290 \mathrm{~nm}$ の波長領域にきわめて強 い吸収帯を示すが，240２65 nm の領域には殆ど吸収帯 を示さないためオキシン銅の定量を妨害しないことが明 らかであり，微分スペクトル法のすぐれた点ということ ができる。

\section{引用 文 献}

1) 後藤真康 ・加藤誠哉：残留農薬分析法, ソフトサ イエンス社, p. 198, 1980

2) M. Maeda \& A. Tsuji: Chem. Pharm. Bull., 27, 797 (1979)

3）小野成男：農薬誌 7,481（1982）

4）小野成男・遠山典宏：農薬誌 7,363 (1982) 